\title{
LÍMITES CONCEPTUALES \\ DE LA COMPETENCIA LITERARIA CONCEPTUAL
}

\author{
BOUNDARIES OF LITERARY COMPETENCE
}

\author{
José RIENDA \\ Universidad de Granada \\ jrienda@ugr.es
}

Resumen: El concepto de competencia literaria ha venido siendo vinculado y subordinado al de competencia comunicativa. Este trabajo define los límites conceptuales entre ambas nociones y defiende los valores de la especificidad de la didáctica de la literatura.

Abstract: The concept of literary competence has been linked and subordinated to communicative competence. This paper defines the conceptual boundaries between the two notions and defends the values of the specificity of the teaching of literature.

Palabras clave: Competencia literaria. Competencia comunicativa. Didáctica de la literatura.

Key words: Literary competence. Communicative competence. Teaching of literature. 


\section{INTRODUCCIÓN}

La conceptuación de la literatura, en cualquiera de sus géneros, ha venido tradicionalmente marcada por un exceso taxonómico en función de la instrumentación e intencionalidad pretendidas al considerarla como objeto de estudio. En efecto, «el concepto de Literatura parece ser un campo de Agramante [...] según la óptica ideológica desde la cual se parta. El concepto de arte literario diferirá para el crítico existencialista, marxista, burgués, etc.» (Romera, 1988: 139). En este sentido, consideramos que la multiplicidad semántica del concepto de literatura posibilita a su vez el otorgamiento a su conceptuación de una triple dimensión: ontológica, social-axiológica y academicista — que matizamos enseguida—, más la derivación hacia el que podíamos denominar corpus paidológico — validable tras la reciente consideración histórica de la literatura infantil como género independiente al margen de los géneros literarios tradicionales-, el cual, en primera instancia, requiere el establecimiento del canon preceptivo:

para avanzar un paso más en la construcción de la didáctica de la literatura en la etapa infantil, el siguiente aspecto que debe abordarse es el de las obras y autores que han de formar parte de ese acercamiento a lo literario (Pozuelo Yvancos, 1996: 3-4), es decir, el canon escolar de la literatura infantil, $y$, ciertamente, dada la profusión de títulos que en los últimos tiempos genera el mercado editorial sobre lo que genérica y no siempre acertadamente se denomina literatura infantil, se hace imprescindible un deslinde crítico entre los textos que deben formar parte de ese canon y los que no (Núñez, 2009: 141).

Esto es, estaríamos ante la necesidad de «un canon formativo, elaborado bajo el criterio de la operatividad y la funcionalidad didácticas, y encaminado al desarrollo de la competencia lectora y literaria» (Núñez, 2009: 142), criterio este de operatividad y funcionalidad didácticas que, precisamente, nos obliga al referido otorgamiento conceptual desde la triple dimensión referida, dada la ya mencionada multiplicidad semántica del concepto de literatura:

a) Una dimensión ontológica, en la que la gnoseología y los sistemas epistemológicos amén de la versión historicista establecerían aquí los límites conceptuales.

b) Una dimensión social-axiológica, donde se ubica cierta instrumentación de agente con manifiesta intencionalidad política, religiosa, etc., ideológica en definitiva. 
c) Y una dimensión academicista en la que el estudio del texto literario se ha convertido también en objeto de estudio — esto es, de la filología a la ironía sesgada de la crítica de la crítica crítica (Rodríguez, 1994: 7), pasando por la teoría de la literatura y su corazón periférico (Chicharro, 2006)—.

Con todo, la traslación del conocimiento literario desde la singular perspectiva del docente no es determinada unívocamente en función de la contemplación de la literatura como concepto aprehendido desde el academicismo, la axiología u ontología y ni tan siquiera con obligatoriedad hacia el referente paidológico, sino que, más bien, se conformaría atendiendo en diversidad de grado a tales dimensiones conceptuales. Así, consideramos que son defendibles en el ámbito de la didáctica de la literatura cuatro formas de abordar el conocimiento literario: el acercamiento estructural, donde la construcción literaria es determinada desde la especificidad estética y academicista; la focalización intencional — para el doble momento de la escritura y lectura- , íntimamente vinculada a la dimensión social-axiológica; el aprendizaje autónomo — en tanto que las guías de trabajo autónomo han mostrado su eficiencia para la adquisición del saber tanto ontológico como academicista de la literatura-; y la derivación multidisciplinar o transdisciplinar de la literatura (Rienda, 2006a: 6).

A estas cuatro formas de abordar el conocimiento de la literatura establecidas para su didáctica, habremos de adjuntar ahora el concepto de competencia literaria en atención a los rumbos actuales de las didácticas específicas, por lo que consideramos de inmediato la necesidad de una conceptuación válida y suficientemente sólida de competencia literaria como requisito previo e ineludible a cualquier plan de intervención en el ámbito docente.

\subsection{La competencia literaria en didáctica de la literatura}

En Educación Obligatoria, el desarrollo de la competencia literaria ha de entenderse como recurso válido para la mejora de la competencia comunicativa —aunque, veremos, no necesariamente como única vía funcional—. Sin embargo, junto a otros autores (Olsbu, 2006: 3), coincidimos en la problemática conceptual derivada de la unión de los términos competencia y literatura.

Es sabido que el origen específico del término competencia está vinculado a la formación profesional y la reforma de la formación del profesorado realizada en Estados Unidos en los últimos años de la década de los se- 
senta (Tuxworth, 1989). De hecho, es lugar común situar en EE.UU., en los años veinte, el origen la formación basada en competencias (FBC), enfoque que fue «inaugurado por las reformas educativas requeridas por los sectores industriales y comerciales, que reclamaban una mayor atención a los resultados especificados en formas conductualmente objetivas» (Blas, 2007: 1). Concretamente:

con motivo de la creciente insatisfacción social por los mediocres resultados de la formación elemental o básica y de las numerosas demandas que reclamaban la reforma de la formación del profesorado de esta etapa educativa, la Oficina de Educación de Estados Unidos encargó estudios sobre programas de formación para la preparación del profesorado de la escuela elemental. [...] La formación del profesorado basada en la competencia se convirtió en un movimiento cuyo enfoque fue asumido por algunos Estados de USA, que aplicaron procedimientos de certificación de la competencia a los aspirantes a la función docente. A pesar de las críticas que provocó este enfoque [...], la Oficina de Educación lo siguió apoyando a través del National Consortium of Competency Based Education Centres, que desarrolló un conjunto de criterios para describir y evaluar los programas basados en la competencia. Estos criterios anticiparon hace más de tres décadas los rasgos fundamentales que caracterizan lo que hoy día se conoce como enfoque de la formación basada en la competencia (FBC) (Blas, 2007: 1).

En España, la LOGSE (1990) favoreció la inercia de la formación en competencias particularizada desde un enfoque funcional-comunicativo, trasladando así la $F B C$ a la reforma específica de la formación profesional reglada para, después, hacerse extensiva desde la Educación Obligatoria hasta el Espacio Europeo de Educación Superior con la Declaración de Bolonia (1999).

Esta alusión al origen y desarrollo de la $F B C$ y su prolongación hacia la formación competencial generalizada, resulta obviamente necesaria para la fijación del concepto de competencia comunicativa. A partir de aquí constatamos que la designación de competencia difiere ya bastante de lo designado en su origen:

The intention was to place the primary emphasis on outputs (an account of the specific occupational role broken down into performance statements) and to recognise that the particular inputs (training courses, work experience, prior learning) were contingent; it matteered more what prospective employees could actually do, not what training they had attended (Fleming, 2006: 2). 
No obstante, una característica destacable es el hecho de que, desde el primer momento, siempre se ha venido marcando la importancia del resultado, o lo que para nosotros sería el valor determinante del producto final del proceso de aprendizaje. Por tanto, lo que nos interesaría como docentes desde el concepto de competencia como referencia es, precisamente, lo que sabe hacer el alumno con los conocimientos que ha adquirido (Olsbu, 2006: 3). Sin soslayar en ningún momento la dificultad añadida que supone la evaluación no ya de la adquisición de destrezas, sino también de la instrumentalización que de ellas realiza el alumno, surge de principio una cuestión nodal para nosotros, pues ocurre que la literatura, la experiencia literaria, supone en cierto modo un desequilibrio ante la concepción generalizada de competencia. En efecto, por un lado tenemos, por ejemplo, que:

Literatura es arte, aliento poético, tensión (...). Está hecha de imaginación lingüística y de asociaciones nuevas, distintas y fecundas. Literatura es desviarse del camino trillado y cotidiano, de las frases gastadas y manidas (...). Literatura es descubrir e iluminar por dentro la realidad que nos rodea. Literatura es creación fértil de mundos que se sostienen en pie por la sola virtud de la palabra (...). ¿Qué anhelo? ¿Qué ansia imponderable lanza un ser humano a la literatura? (...) Catarsis, compromiso, arte por el arte, sentimiento lúdico, apertura al infinito, ansia de inmortalidad (...). La literatura, que es expresión del hombre y la sociedad, conforma y configura al hombre y la sociedad (García Madrazo, 1991: 18-19).

Y por otro lado, si sabemos que leer literatura es sinónimo de una serie de encuentros «en los que se ven involucrados tanto la cultura-meta, el autor, la experiencia personal del alumno y la influencia del profesor. ¿Cómo medir los resultados de estos encuentros? ¿Qué competencias activamos y fomentamos en el alumno al trabajar con un texto literario?» (Olsbu, 2006: 4).

Sin embargo, no resultaría complicado en exceso marcar correlaciones entre la competencia literaria y el consabido listado de competencias genéricas o transversales, pues la misma dificultad que encontramos para especificar las competencias que activamos al trabajar con un texto literario es, a la inversa, la que hace posible una correlación casi global con el mencionado listado de genéricas. En efecto, no estamos en condiciones de negar que el hecho literario, en toda su amplitud, ayuda al saber hacer del alumno en el marco no ya de la competencia comunicativa, sino en el espacio genérico de la transversalidad. Así, en el proceso de desarrollo de la competencia literaria se incorporan casi en pleno las competencias instrumentales - capacidad de análisis y síntesis, capacidad de organización y planificación, co- 
municación oral y escrita, capacidad de gestión de la información, toma de decisiones-, las personales — trabajo en equipo de carácter interdisciplinario, reconocimiento a la diversidad y la multiculturalidad, razonamiento crítico, compromiso ético-, las sistémicas —aprendizaje autónomo, creatividad, conocimiento de otras culturas y costumbres, motivación por la calidad, sensibilidad hacia temas medioambientales - y otras — capacidad de aplicar los conocimientos teóricos en la práctica, uso de Internet como medio de comunicación y como fuente de información, experiencia previa, capacidad para comunicarse con personas no expertas en la materia, capacidad de entender el lenguaje y propuestas de otros especialistas, ambición profesional, capacidad de autoevaluación-.

Es cierto que la irrupción de las competencias en la educación obligatoria ha facilitado el establecimiento de unos mínimos o cotas adquiribles que, de manera efectiva, engloban los objetivos y destrezas definidos en los niveles de cualificación contemplados en los programas curriculares de lengua española. En este sentido, el concepto de competencia comunicativa supone en sí mismo la piedra primera sobre la que habrán de desarrollarse el resto de las competencias específicas, siempre al amparo del enfoque comunicativo en su doble vertiente funcional y significativa:

Los enfoques basados en presupuestos funcionalistas y comunicativos [...] han repercutido en el campo de la didáctica de la lengua materna y, en general, han aparejado una evolución del mismo en el sentido de que la atención ha ido pasando de la lengua como objeto de conocimiento al uso u funcionalidad de la misma (Núñez, 2003: 72).

Por tanto, surge una necesidad de consideración global de términos como competencia lingüística o capacidad innata; competencia sociolingüística o capacidad de adecuación; competencia estratégica o capacidad de regulación de la interacción; competencia textual o discursiva, o capacidad de producción y comprensión de diversos tipos de textos; competencia semiótica o conocimientos, habilidades y actitudes en el análisis; y competencia literaria o capacidad para la producción y comprensión de diversos textos literarios. En definitiva:

es responsabilidad de todos los docentes, al margen de su área de conocimiento, prestar especial atención al papel del lenguaje como mediador en los complejos procesos que se producen en el aula: estrategias didácticas, modos de organización del trabajo, comunicación entre alumnos y profesor y de alumnos entre ellos, posibles déficits lingüísticos... (Núñez, 2003: 78). 
Es lógico entonces pensar que «la Lengua y la Literatura son como dos trayectos de tren en una misma dirección, que van trazados paralelamente, aunque, en ocasiones, se produzcan entrecruzamientos entre ellos» (Romera, 1999: 127-128). En este sentido:

utilizar la Literatura como modelo lingüístico puede ser rentable desde diversos planos: desde el estrictamente lingüístico, nos ofrece la posibilidad de aprender un modelo de lengua bello, culto y pulido; desde el específicamente humano, contribuye a una formación integral más completa del individuo [...]; desde el hedonismo, nos permite gozar del placer de la lectura [...] y, en fin, con el uso de los textos literarios la tarea didáctica no se hará tan ardua (Romera, 1999: 128).

A partir de aquí, en los objetivos del docente que se concretan administrativamente para el área de didáctica de la lengua y la literatura, podemos establecer una distinción entre objetivos de carácter instrumental para el desarrollo de la competencia comunicativa, objetivos específicos de la competencia literaria vinculados a la competencia comunicativa y, por último, objetivos específicos unívocos de la competencia literaria (Rienda, 2007a: 32-34). Sabemos que cualquier formulación curricular supone en sí misma un debate desde el primer momento en el que se establecen los componentes teóricos y prácticos que serán la base dicha formulación, en tanto que el currículo es la concreción de los fines últimos asignados a la escuela, esto es, fines de socialización en última instancia (Gómez-Villalba, 2000: 15). Y en efecto, en palabras de Núñez Delgado, el currículum escolar constituye, por tanto, un punto de encuentro entre el saber y el poder, de tal manera que no es posible hablar de currículum escolar «sin estar inmerso en el pensamiento sobre el papel social de la escuela, es decir, en la entraña de la teoría escolar, para poder así centrarse especialmente en los conocimientos que se han de enseñar-aprender y en la adecuación de los contenidos pedagógicos y didácticos en función de los fines de la educación y de la enseñanza en orden a la formación del educando» (Núñez, 2003b: 47).

Con todo - y como de algún modo ya hemos anunciado— observamos que, tres lustros después de la Reforma del Sistema Educativo referida, no ha mudado en mucho nuestro edificio docente a pesar del nuevo abordaje terminológico. En efecto, al comienzo de los años 90 y amparados en los barandales del Diseño Curricular Básico, la enseñanza de la literatura ya reclamaba abiertamente los perfiles actuales, llamando la atención la importancia que entonces se daba a la comunicación oral o la alusión explícita a 
contenidos conceptuales, procedimentales y actitudinales en los distintos bloques de contenido:

En la introducción de los actuales programas renovados se afirma que «enseñar lengua española consiste en enseñar a utilizar la lengua española» y continúa diciendo que los contenidos no son un objetivo en sí mismo; sino «enseñanza complementaria y auxiliar de lo fundamental, que es saber hablar, leer y escribir con fluidez y soltura». ¿Qué es, entonces, lo que hace que estos planteamientos aparezcan como novedosos? Creemos, sin ningún género de duda, que es el currículo entendido como instrumento de cambio e innovación. [...] Lo que entra en cuestión desde esta perspectiva es el mismo proceso de enseñanza que en ningún momento queda disociado del proceso de aprender [...]. El Proyecto curricular está encaminado no solo al desarrollo del conocimiento sino también a cómo se desarrolla el conocimiento (Navarro, 1992: 53-54).

Entonces se hablaba de un D.C.B. con tres características destacables en función de sus implicaciones didácticas en el área de Lengua y Literatura: uno, el carácter abierto del currículum — con los consabidos riesgos pedagógicos y las necesidades formativas por parte del profesorado derivados de los sucesivos niveles de concreción de objetivos y contenidos (García, 1995: 133-136) ante el peso de la tradicional visión historicista del área-; dos, su dimensión global e integral — con la exigencia conceptual de lenguaje instrumentalizado y la resignación ad hoc de la literatura como recurso didáctico de optimización discursiva-; y tres, la concepción constructivista de la enseñanza y el aprendizaje que asume el currículo, con la integración de la teoría genética del aprendizaje, la teoría del aprendizaje verbal significativo de Ausubel y la teoría esquemática de la estructura cognitiva del sujeto. Aclaramos en este punto, primero, que la teoría genética es matizada por las teorías de la antropología cultural, y sostiene que los nuevos aprendizajes deben realizarse siempre a partir de los conceptos, representaciones y conocimientos que ha construido el alumno en el transcurso de sus experiencias previas; en segundo lugar, recordamos que la teoría del aprendizaje verbal significativo de Ausubel sostiene que el nuevo material de aprendizaje se relaciona de forma significativa y no arbitraria con lo que el alumno ya sabe, produciéndose entonces un cambio en la estructura cognitiva previa; finalmente, señalamos que la teoría de los esquemas concibe la estructura cognitiva del sujeto como un conjunto de esquemas de conocimiento que recogen una serie de informaciones que pueden estar organizadas en mayor o menor grado $\mathrm{y}$, por tanto, ser más o menos adecuadas a la realidad por su correlato con las teorías de la comprensión, las cuales, por su parte, sostienen que la comprensión 
es un proceso a través del cual el sujeto elabora un significado en función de la información almacenada en su mente (Navarro, 1992: 54-57).

Con todo, la forma o enfoque de aprehensión de la competencia comunicativa en el D.C.B. continúa siendo válida y coordinante a la vez, lo que, en función del esquema ilustrativo de las aportaciones de Navarro Martínez reseñadas (Navarro, 1992: 56), ordenamos y reorganizamos para puntualizar la cuestión literaria — ganando además la justificación sobre «el tratamiento de la literatura desde teorías como la de la recepción literaria o la del procesamiento cognitivo de la literatura» (Navarro, 1992: 57), es decir, la presentación de la literatura al alumnado no como algo establecido e incólume, sino como un hecho en acto (Iser, 1987) dada la involucración del receptor y su capacidad hermenéutica-:

a) El lenguaje interviene en el desarrollo de la persona, pues, por un lado, regula el pensamiento y la conducta, y, por otro, facilita la adquisición de conciencia del entorno y la vida social y cultural.

b) El lenguaje es funcional, pues: uno, está vinculado al ejercicio docente/discente en el aula y a las necesidades generales de comunicación; y dos, desarrolla la comprensión — escuchar, leer — y la expresión — hablar, escribir-.

c) El lenguaje adquiere carácter metalingüístico, pues reflexiona sobre los mecanismos de la lengua concretándose, por ejemplo, en la gramática —entendida siempre con carácter instrumental—.

d) El lenguaje posibilita la manipulación de textos, tanto orales/escritos como literarios/no literarios. Los textos literarios son modelo de escritura, son fuente de lectura, intervienen en el desarrollo de la estética discursiva, estimulan la fantasía y creatividad y promueven la actitud crítica.

e) El lenguaje posibilita el reconocimiento de la realidad plurilingüe y pluricultural.

La derivación histórica de la FBC ha desembocado, por tanto, en una prolongación de los planteamientos anteriormente tratados, hasta el punto de que hoy día se afrontan los mismos con el propósito más de realizar algunas matizaciones en superficie que de buscar y forzar su revisión en profundidad. Evidentemente, esto último no se trae a colación como crítica factible desde la simpleza revisionista, sino como dato que revalida las propuestas de renovación del pasado inmediato y, sobre todo, como fortalecimiento de las líneas de actuación desarrollables para la enseñanza de la 
literatura en la actualidad. En este sentido, Pedro C. Cerrillo menciona cuatro pilares sobre los que el futuro profesor debe establecer su concepto de la enseñanza de la literatura:

1. La defensa del atractivo de la lectura de la obra literaria en sí misma.

2. La aceptación de las interpretaciones personales que cada receptor haga de la lectura de la obra literaria.

3. La concienciación sobre los valores formativos de la lectura literaria.

4. El trabajo simultáneo de lectura significativa y escritura significativa (Cerrillo, 2007: 19).

Y continúa:

Las diferentes perspectivas desde las que, didáctica y científicamente, puede abordarse la esencia del fenómeno literario, nos demuestran que debe adoptarse un criterio ecléctico y plural, sin exclusividades. Esta opción integradora se justificará tanto por la diversidad de las teorías existentes como por la complejidad de la obra literaria, aunque, en cualquier caso, hay algunos aspectos de atención casi inexcusables: a) Todo acercamiento al texto literario debe tener en cuenta que la literatura es un acto de comunicación de características especiales que afecta al conjunto de elementos intervinientes en él, y que no puede explicarse por uno solo de ellos. b) La obra literaria es producto de una cultura y de un contexto cuyo significado habrá que interpretar, por tanto, en el marco de un sistema cultural, que, además, es cambiante. c) Los participantes en la comunicación literaria deben tener la competencia literaria que les permita acceder a la codificación literaria, más allá de la puramente lingüística. Esta competencia debe ser adquirida por medio de mecanismos diversos: que procedan de los mismos textos literarios o que sean ajenos a ellos (factores históricos, sociales o culturales). d) La obra literaria, admitida como tal, se comunica mediante un lenguaje especial, el lenguaje literario, que emplea unos artificios expresivos que los separan del lenguaje estándar (Cerrillo, 2007: 19).

\section{CONCEPTUACIÓN DE DIDÁCTICA DE LA LITERATURA}

Antes de establecer nuestra conceptuación de competencia literaria y sabiendo que, según hemos apuntado, en última instancia la competencia literaria habría de entenderse como recurso no suficiente, pero sí valido y funcional para la mejora de la competencia comunicativa, junto a la necesaria historiación transitada en las páginas precedentes y la intencionada alusión a la teorización que legitima cualquier acto de intervención didáctica, 
consideramos necesario un establecimiento de límites que enmarquen la noción de didáctica de la literatura que siempre hemos mantenido en nuestro horizonte de reflexión y que, en definitiva, habrá de acoger la derivación factible hacia la práctica de cualquier base teórica desarrollada.

Nuestro punto de partida está en la certeza de que «la literatura es un instrumento válido en la formación de los individuos porque se proyecta sobre la problemática vital de los individuos, sirve para transformar la realidad y, a la vez, es instrumento de goce y placer» (Romera, 1988: 145). Por eso se hace imprescindible la concesión a la literatura de la ya referida dimensión ontológica:

Porque en definitiva lo que aquí importa no es solo lo que la literatura pueda decir de ella misma explícitamente, sino el hecho de que exista una literatura del saber, un saber que [...] impone efectuar el reconocimiento de su radical identidad: la literatura es una forma de conocimiento (Chicharro, 1987: 51)

En efecto, la literatura, entre otras muchas cosas, es una forma de conocimiento. Es decir, es posible conocer el mundo a través de la literatura (Whanón, 1991: 132-138; Chicharro, 1987: 44-54). Del mismo modo, la literatura es también un vehículo de aprehensión del conocimiento; esto es, podemos ejercer como docentes de lo universal con la literatura como recurso en tanto que posibilita el hecho didáctico; o lo que es lo mismo, es posible enseñar el mundo a través de la literatura y, por tanto, es posible que los alumnos conozcan —aprehendan, decíamos - el mundo a través de la literatura. En este sentido y por ejemplo, el profesor Mata (2004) fortalece la confianza en los libros y la literatura como vía de adquisición del conocimiento a través de la lectura, a través de la forma en que se accede a la lectura y, especialmente, a través de la forma en la que el niño se relaciona con la lectura y cómo se conduce esa relación desde la perspectiva del docente y del educador en general:

Quiero decirte que no todos los abogados de la lectura hablan tu mismo idioma, no todos comparten tus mismos sueños. Confía, pues, en tu coraje y en tu entusiasmo, busca a tus cómplices y comparte con ellos tu esperanza, lee infatigablemente cuanto caiga en tus manos, piensa siempre en el porvenir de tus alumnos. Haz de los libros y de la lectura tu personal compromiso a favor de los niños y de la vida, convierte la literatura en un elemento tan primario como el alimento, el abrigo o las caricias. Renovarás así el pleno significado de este postrer poema de Pablo Neruda que te ofrezco. [...] Los 
libros tejieron, cavaron, / deslizaron su serpentina / y poco a poco, detrás / de las cosas, de los trabajos, / surgió como un olor amargo / con la claridad de la sal / el árbol del conocimiento (Mata, 2004: 134-135).

Porque la literatura no solo se escribe desde la intencionalidad y productividad, sino que en potencia también se lee intencional y productivamente con probada validez incluso desde la funcionalidad temática ${ }^{1}$ - fruición, sí (Chicharro, 1987: 55), pero también búsqueda de ese árbol del conocimiento- - Así, nuestro objeto de estudio y trabajo, la literatura y su didáctica, también la literatura infantil, se despliega universal en su doble faceta historiable: primera, la literatura como escritura — que en última instancia es un acto comunicativo con el riesgo de la inconcreción-; y segunda, la literatura como lectura, esto es, como elemento inteligible por parte del lector - soportando en amplia medida el riesgo, y valor a la vez, de la multiplicidad-. Ambas facetas, escritura y lectura literarias, son historiables; o lo que es lo mismo, se pueden reducir a estudio tanto la historia de la literatura — convencionalismo - como la historia de la lectura, con implicaciones interesantes derivadas, por ejemplo, de la lectura en acto ya referida (Iser, 1987):

La lectura de una narración [...], como causa debida, otorga la medida exacta del valor de los libros como objeto, entes a los que todo lo expresado se les debe y que cuentan incluso con anatomía propia: cabeza, falda, recto, pie, cartivana, cabezada, verso, medianil, portada, cajo, cantonera, lomo, nervio, lomera, colofón, canal, guarda... Los libros son un preciado objeto del deseo, pues, sabemos, el libro como objeto en sí mismo, también como fetiche sin duda, anda ligado al concepto de propiedad desde el germen de

1 Wolfgang Iser concluye en su trabajo El acto de leer que el significado de una obra literaria no se puede considerar en esencia, sino en acto, en tanto que leer es una acción donadora de sentido en la que interviene el sujeto lector guiado en su actividad imaginativa y hermenéutica por los estímulos textuales. Se trata de una propuesta teórica próxima a la pragmática que se singulariza desde la idea de la recepción estética, pues, tanto la pragmática como el principio recepcionista, establecen puentes de relación sólidos entre lector, texto y autor.

Sobre tal retablo de la literatura, entendida como discurso cohesionado, desde los tres planos aludidos —autor, texto, lector—, se hace posible y necesaria también su ampliación y superación relacional. Así, en un intento de - y permítanme el término- desindividualización de la construcción literaria, resulta oportuno trasladar hasta aquí la apertura que Claudio Guillén conceptuó como tematología, con la certeza, siempre, de que los estudios o exploraciones tematológicos no circulan desabrigados de fundamento teórico, pues son abordados desde el amplio marco de la literatura comparada.

$\mathrm{Y}$ es en este espacio, precisamente, donde la noción de tema literario adquiere importancia y autonomía, pues, en definitiva, la relación temática hallada entre autores y textos diversos y el análisis funcional de dicha relación temática frente al lector, tallan, felizmente para nosotros, nuevas aristas en el diamante literario (Rienda, 2007a: 31-32). 
su existencia [...]. Ocurre, abundando aún más en este asunto, que no aludimos únicamente al concepto de propiedad privada atribuible a un soporte de la lectura con un determinado número de páginas y un gramaje de papel generoso [...], por ejemplo. En este caso nos referimos también a la propiedad privada de la historia que contiene ese soporte de información. Cuando un libro cae en manos de un lector, en ese instante preciso, su escritura, su contenido, deja de pertenecer al autor para adecuarse a la vida de quien lo lee, a la mirada de quien lo lee, al mundo de quien lo lee. El lector, anónimo y múltiple, es quien dará sentido a la escritura, y la escritura, como sabemos, es el surco del tiempo (Rienda, 2007b: 22-23).

Si el lector, anónimo y múltiple, es quien otorga sentido a la escritura, ganamos por tanto que la literatura nos ofrece de igual modo la posibilidad de esa doble faceta historiable también para la actuación didáctica.

Y ocurre además que con los mismos términos nos situamos en la vertiente adjunta: la literatura no solo se lee desde la intencionalidad y productividad, sino que en potencia también se escribe — surco del tiempo en la memoria (Lledó, 2000) — intencional y productivamente:

La insistencia en los aspectos instrumentales del acto de escribir no ha dejado ver que quien escribe se coloca en una relación activa, productiva, con aquello sobre lo que escribe. [...] En este sentido, si pretendemos que la escritura pase a ser una herramienta de conocimiento es preciso generar situaciones que pongan a los alumnos en una posición activa y productiva con el objeto que están conociendo. [...] Scardamalia y Bereiter (Scardamalia, 1992), desde la psicología cognitiva, han establecido una crucial diferencia entre lo que ellos llaman decir el conocimiento y transformar el conocimiento (Frugoni, 2006: 78-79).

En efecto, la escritura literaria también gana esa atribución del estar conociendo de forma incontestable:

La escritura literaria como sostén de la condición humana, como defensora de la causa del hombre y su destino, resultaría así una actividad primordial, imprescindible. En la literatura podría rastrearse entonces todo lo que de sublime y abyecto pertenece a la humanidad, su memoria y también sus sueños. $Y$ lo que vale para la literatura de adultos vale igualmente para la literatura infantil y juvenil [y también, añadimos, para la literatura creada por los niños, esto es, escritura con sesgo literario consciente], pues no hago distinciones entre una y otra a la hora de valorar su aportación al conocimiento de los seres humanos y del mundo que vivimos (Mata, 2008: 129). 
Decíamos que consideramos necesario un establecimiento de límites a propósito de la noción de didáctica de la literatura que de alguna manera nos mueve en nuestros propósitos. Dado que, en principio, en Educación Obligatoria de lo que se trata es, más que de enseñar literatura, de usar la literatura como instrumento en el aula —según la concepción de competencia literaria que apuntábamos al principio - y dado su carácter de disciplina teorizable, habremos de entender la didáctica de la literatura en función de: a) el propio término de didáctica; b) su dimensión sistémica; c) su atribución gnoseológica; d) su concreción estructurable; y e) su convergencia interdisciplinar.

El concepto de didáctica se nos presenta con cierto sesgo culturalista en la Europa occidental y, a la par, lacerado por su inamovible vinculación al doblete enseñanza-aprendizaje anglonorteamericano. Desde la acepción familiar que reduce el concepto de didáctica a la simple enseñanza de materias escolares, pasando por el carácter pseudomítico que pretende caracterizarla como don innato e intransmisible para comunicar saberes poseídos, aglutinamos para nuestra conceptuación: uno, su acepción artística —manejar recursos para que los alumnos aprendan o facilitar con normas la interiorización de cultura y modelos de comportamiento positivos para la comunidad o grupo-; dos, su acepción tecnológica — sistemas controlables de secuencias repetibles para la interiorización de la cultura basado en decisiones normativas, prescritas o preceptuadas-; tres, su acepción axiomática - principios o postulados sobre decisiones normativas para el aprendizaje-; y cuatro, su acepción positiva — saber formalmente especulativo, pero virtualmente práctico, cuyo objeto es tomar decisiones normativas sobre los interactivos trabajo-docente-discente- Además, incorporamos al término los consabidos tres espacios didácticos: espontáneo —enseñar y aprender sin saberlo - intencional —enseñanza y aprendizaje conscientes - y sistemático —remodelación del conjunto interactivo de relaciones discentes y docentes en busca de la instrucción-.

Por su parte, la dimensión sistémica de la didáctica de la literatura, es decir, su modificación como sistema, se hace entendible en tanto que es igualmente un conjunto organizado de elementos diferenciados cuya interrelación e interacción supone una función global.

Respecto a la atribución gnoseológica de la literatura, sostenemos que, de algún modo, esta es fundamental en nuestra concepción de la literatura, a la que atribuimos sin dudarlo cualificación y validez para el estudio del valor y alcance del conocimiento humano. Aunque históricamente se han uti- 
lizado diferentes nombres para expresar este concepto —epistemología, metafísica especial, teoría del conocimiento, criteriología...-, nosotros convenimos también en reservar los conceptos de gnoseología para la posible vinculación con la teoría general del conocimiento y epistemología para la reducción de dicha vinculación a la especificad de los distintos saberes científicos - el literario en nuestro caso-. No obstante, habremos de forzar el maridaje mal avenido de epistemología e interdisciplinaridad, pues:

se dice que el reto de la educación permanente, de toda educación en la era de lo fugaz, tiene que ser aprender a aprender y a adquirir las técnicas para acceder al conocimiento vigente en cada momento. Pero solo es posible ubicarse en esa provisionalidad de constructivismo permanente para los que dominan el conocimiento a un cierto nivel: al resto los sume en un vacío cultural. Solo a partir de un cuerpo sólido de conocimiento es posible situar al estudiante ante la perspectiva de la relatividad del mismo [...]. La adopción de un relativismo epistemológico puede vaciar de contenidos la educación (Actis, 1998: 31).

En lo que se refiere a la concreción estructurable de la didáctica de la literatura, es evidente que también la didáctica de la literatura en particular y la didáctica en general articulan en sí mismas el conjunto de elementos que las componen para la ganancia de sentido en referencia a la totalidad.

Por último, la divergencia interdisciplinar de la didáctica de la literatura se sostiene sobre la base pedagógica de la interdisciplinariedad, en tanto que permite activar relaciones de dependencia, posibilita niveles de jerarquización, corrige los riesgos reduccionistas, etc., sin menoscabo del objeto de estudio y sin que por ello se resienta la unidad del corpus pedagógico. En efecto, la educación permite y suscita estudios interdisciplinares, cuyos planteamientos han tenido una fuerte repercusión en los currículos, en las técnicas de enseñanza y, en general, en la planificación de los sistemas educativos. Además:

no se puede tratar el fenómeno literario como si de un reino puro de esencias se tratase. Las relaciones entre literatura y sociedad son culturalmente mutables. [...] Porque lo que existe es una diversidad desbordante, un panorama caótico; tan caótico como plural y enriquecedor. [...] No cabe sino optar por una mirada comparada de la literatura, rebosante ella de múltiples intertextualidades [...], sin abandonar el sesgo interdisciplinario [...], procurando la participación activa del alumnado en la selección, interpretación, discusión, opinión, revisión y reelaboración de las tareas programadas (Moreno, 2008: 184-185). 
Así, llegados a este punto y en función de las nociones arriba tratadas, consideramos que la didáctica de la literatura es un sistema gnoseológicoepistemológico de estructuración interdisciplinar.

\section{CONCEPTUACIÓN DE COMPETENCIA LITERARIA}

El punto de partida para nuestra conceptuación arranca en el establecimiento de la noción de competencia comunicativa. A comienzos de los setenta, Dell Hymes $(1971,1974)$ sentó las bases teóricas de la misma disertando a partir de términos como capacidad, experiencia social, y necesidad y motivación:

La competencia comunicativa es el término más general para la capacidad comunicativa de una persona, capacidad que abarca tanto el conocimiento de la lengua como la habilidad para utilizarla. La adquisición de tal competencia está mediada por la experiencia social, las necesidades y motivaciones, y la acción, que es a la vez una fuente renovada de motivaciones, necesidades y experiencias (Hymes, 1996: 15).

Para Berruto la competencia comunicativa es

una capacidad que comprende no solo la habilidad lingüística, gramatical, de producir frases bien construidas y de saber interpretar y emitir juicios sobre frases producidas por el hablante-oyente o por otros, sino que, necesariamente, constará, por un lado, de una serie de habilidades extralingüísticas interrelacionadas, sociales y semióticas, y por el otro, de una habilidad lingüística polifacética y multiforme (Berruto, 1979: 49).

Por su parte, Girón y Vallejo consideran que la competencia comunicativa comprende «las aptitudes y los conocimientos que un individuo debe tener para poder utilizar sistemas lingüísticos y translingüísticos que están a su disposición para comunicarse como miembro de una comunidad sociocultural dada» (Girón, 1992: 14). A partir de esta conceptuación de competencia comunicativa, y considerándola en definitiva como el conjunto de estrategias, instrumentos y recursos que conforman el conocimiento que necesita el individuo para la optimización de sus mensajes (González, 1999: 32), avanzaremos hacia el pórtico de nuestra propuesta definitoria de competencia literaria amparados en las líneas que hemos desarrollado como bases para su fundamentación histórico-teórica, que ahora ampliamos con precisión conceptual. 
De inicio, somos conscientes de que «los intentos de definir y perfilar el concepto de competencia literaria han puesto de manifiesto la diversidad de componentes que aparecen en las producciones literarias» (Mendoza, 2004: 138). En este sentido, Mendoza Fillola (2004: 138-141) apunta aproximaciones como la de T. A. van Dijk al señalar que la poética teórica, amén de su intento de teorización literaria, debe ocuparse también de la «descripción y explicación de la capacidad del hombre para producir e interpretar textos literarios: la llamada Competencia Literaria» (Van Dijk, 1972: 170). Antes que van Dijk, Bierwisch (Bierwisch, 1970; Aguiar, 1980) ya hizo referencia al concepto de competencia literaria en 1965 (Coloma, 2002: 232), definiéndola como «una adquisición sociocultural, supuesto que los mecanismos poéticos surgen de un concreto modo de expresión cultural» (Mendoza, 2004: 140), esto es, como una competencia que no es innata, sino que hay que desarrollar con el despliegue intensivo de actividades e intervenciones propias de la perspectiva generativa de la educación literaria (Tabernero, 2003: 316). Thomas (1978) sostiene que, efectivamente, «la competencia literaria no es una facultad general, sino una aptitud aprendida y es una facultad derivada en relación con la competencia lingüística» (Mendoza, 2004: 140).

En 1975, Culler (1975: 113-130) también participó de esta etapa de gestación del concepto en la que predomina la tendencia generativa (Coloma, 2002: 232; Aguiar, 1980):

J. Culler (1975: 169) define la competencia literaria como el conjunto de convenciones para leer los textos literarios. Y tras esa concisa definición, advierte que la problemática que supone hablar de competencia literaria implica la distinción entre lectores competentes y lectores menos competentes, en correlación con su capacidad para realizar una lectura correcta. Cuando J. Culler se refiere a la competencia literaria como saberes para leer literariamente en realidad lo que hace es afirmar que en la lectura literaria opera un proceso de descodificación y de comprensión que asigna valores especiales a las unidades lingüísticas, en virtud de convencionalismos estéticos y discursivos, entre los que destacan: a) el condicionantes sociocultural que permite el reconocimiento de las marcas o indicios literarios en un texto; b) el conocimiento de los códigos literarios y de las relaciones de intertextualidad; c) los particulares conocimientos metaliterarios; y d) la propia experiencia lectora (Mendoza, 2004: 140).

Una década más tarde, en 1987, Stubss abunda en la misma línea, al considerar que «la competencia literaria supone la capacidad de comprender 
distintos tipos de relación semántica, entre lo que se dice y lo que se implica» (Stubss, 1987: 204; Mendoza, 2004: 140), hasta que ya en 1988 se establece el doble nivel de la competencia literaria por Mendoza y Pascual (1988: 32): el nivel primario, cercano al conocimiento intuitivo; y el nivel «basado en el aprendizaje, la adquisición socio-cultural, en el reconocimiento consciente derivado de los modelos y contenidos de instrucción».

En efecto, «la presencia de una competencia literaria solo es posible constatarla a partir de los efectos - comprensión, reconocimiento estético, actitud lúdica, goce artístico o intelectual...- que el mensaje provoca en el lector» (Mendoza, 2004: 138), esto es, la capacitación para el proceso hermenéutico en última instancia.

En cualquier caso, sabemos que si la competencia literaria permite reconocer, identificar y diferenciar producciones literarias, esto no posibilita sin embargo la definición de literatura — punto en el que han sido mostradas numerosas limitaciones por parte de la crítica teórica—, lo que condiciona igualmente y de inmediato cualquier intento de definición de competencia literaria (Mendoza, 2004: 138):

Si no existe una competencia literaria innata, si no existe, por lo tanto, una gramática literaria universal genéricamente determinada, que corresponda a la gramática universal chomskiana, si por competencia literaria se entiende el conocimiento por parte de algunos hablantes/escritores y de algunos hablantes/lectores, de un sistema de reglas cuya constitución y adquisición dependen de factores variables de orden histórico-contextual, se hace lógicamente inviable formular una gramática literaria que proporcione, como pretende van Dijk, un algoritmo que enumere formal y explícitamente un conjunto virtualmente infinito de textos literarios, que caracterice explícitamente todos los textos literarios posibles bien conformados, todas las estructuras posibles de un texto, aplicándoles una descripción estructural (Aguiar, 1980: 110).

Desde aquí habremos de constatar nuestra derivación de competencia literaria, no sin antes restablecer ciertas constantes ya entrevistas. En primer lugar, la tendencia generativa en la etapa de gestación del concepto y después la resignificación de la literatura desde la prelación del enfoque comunicativo, nos instan a lanzar un primer aviso para navegantes:

No podemos analizar una obra literaria solo desde la perspectiva de otras disciplinas que [...] se limitan a observar su funcionalidad o no, su 
comunicabilidad o no. Si procedemos de esa forma, olvidando la especificidad de la Literatura, corremos un gran riesgo: someterla a un análisis que no la contempla como objeto de estudio (Delia, 2006: 14).

¿Nos veremos de nuevo obligados a reinventar la enseñanza de literatura como «un modo de pensar el lenguaje rico en significados y en experiencias, más allá de los meros afanes comunicativos» (Bombini: 2006: 119)? La potenciación de la competencia literaria debe servir para poner a disposición de los alumnos una lengua, sí, pero también una producción cultural inestimable «no para seguir discutiendo si vale o no vale la pena, si es un discurso social más u otra cosa, si los chicos se van a aburrir o no, sino para alimentar la certeza previa de que los adolescentes y los jóvenes están ahí, alertas y curiosos, dispuestos y críticos» (Bombini: 2006: 119), concluyentes en su libre expresión sobre aquello que solo a través de la literatura podrán conocer. Sin duda, estaríamos obligados a incluir en nuestra concepción de competencia literaria los mínimos establecidos por Cerrillo en los ya mencionados cuatro pilares sobre los que habría de establecerse la enseñanza de la literatura (Cerrillo, 2007: 19).

Por otro lado, la exigua cuota de teoría y definición de la competencia literaria que hemos traído hasta aquí, sí se nos presenta suficiente para atisbar que, de algún modo y casi con metódica paliación, se ha venido estableciendo una clave dicotómica entre competencia literaria y capacitación de y por la lectura. Es decir, las varias conceptuaciones de competencia literaria que hemos trasladado se centran sobre todo en el proceso lector — con deferencia hermenéutica, eso sí- dejando de lado otros factores que marcarían la singularidad formal de la especificidad literaria, el hecho gnoseológico-literario e incluso la propia creación o composición escrita con intencionalidad literaria por parte del alumnado ${ }^{2}$. Es destacable

2 Coincidiendo con Romero López (1989: 9-25) y tal y como apuntamos en otro lugar, «de todos los intentos de definición o conceptuación de composición escrita expresados en numerosas ocasiones y lugares, el más indicado para nosotros es el que por composición escrita entiende “el complejo proceso intelectual que va desde los primeros ejercicios, en los que los alumnos redactan frases sencillas, hasta la página en la que logran expresar libremente sus ideas y estampar el producto de su imaginación” (Sánchez, 1972: p. 15). Es destacable que con la anterior definición se solventa la dificultad teórica que podría surgir al plantearse las posibles delimitaciones terminológicas derivadas de los términos composición escrita, composición literaria o redacción. O dicho de otro modo, con la definición anterior se evita la lamentable confusión que existe entre algunos docentes entre escritura y composición escrita. Ni que decir tiene que el objetivo del profesor en lo tocante a la enseñanza de la composición escrita es desarrollar la capacidad de expresión de los alumnos hasta conseguir un estilo personal a través de la expresión original y coherente de ideas, pensamientos, sentimientos y vivencias en un lenguaje correcto» (Rienda, 2006b: 5-6). 
el hecho de que, en la actualidad, cualquier planteamiento de competencia literaria requiere la incorporación del concepto de intertexto, «en cuanto a que la educación literaria está centrando su atención en el proceso y la actividad del lector, en la participación de éste en la interpretación de un texto literario» (Perdomo, 2005: 149). El intertexto es definido por Mendoza como:

el esencial conjunto de saberes, estrategias y de recursos lingüísticoculturales que se activan a través de la recepción literaria para establecer asociaciones de carácter metaliterario e intertextual y que permiten la construcción de conocimientos significativos de carácter lingüístico y literario que se integran en el marco de la competencia literaria (Mendoza, 1999: 21).

Además, la inclusión del concepto de intertexto ha posibilitado que el desarrollo de la competencia literaria suponga para el citado Mendoza el desarrollo de los distintos saberes que la integran (Romero, 2001: 139):

a) los referidos al saber cultural enciclopédico; b) los referidos a las modalidades discursivas; y c) los saberes estratégicos. Desde esta convicción, «la competencia literaria se considera el eje de esa progresiva selección de conocimientos aportados entre otros factores por el sucesivo enriquecimiento del intertexto» (Mendoza, 1998: 182-183; Romero, 2001: 139).

Con todo y sin menoscabo del valor del la lectura en sí misma, ¿por qué no puede estar entre nuestros propósitos docentes el persuadir al alumno de que «él escribirá un buen cuento cuando junte un contenido, un tema, un argumento, una trama valiosa, en un estilo bello y lleno de colorido y originalidad» (Campa, 2007: 18)? O expresado de otro modo, ¿por qué no debe ser parte principal de la competencia literaria la producción literaria? Constatamos que si:

actualmente, en el campo de la Psicología de la Educación y de las didácticas, es aceptada la idea de que la adquisición y desarrollo de todo conocimiento debe partir de contenidos específicos que posea el sujeto [...], tan importante es tener en cuenta los conocimientos previos que posee el sujeto como el que el propio sujeto sea el protagonista de su formación. Nuestro acercamiento a la literatura debe tener en cuenta estas ideas y debe hacerse, por tanto, de forma significativa y activa, como apuntan Reyzábal y Tenorio (1992: 55): «La literatura [...] debe vivirse, y 
esto se produce cuando los alumnos hacen literatura mediante la escritura, ellos cuentan sus historias, se las leen a los otros, debaten...» (Romero, 1999: 283).

\subsection{Una propuesta de definición de competencia literaria}

Llegados a este punto, es el momento de realizar nuestra propuesta de conceptuación o definición de competencia literaria, sabiendo que la dotación de sentido en todos sus términos viene determinada por la totalidad de las páginas precedentes, validación esta que nos llevó a transitar por la mencionada historiación y teorización de las nociones de competencia, competencia comunicativa, competencia literaria y, en parte, de didáctica de la literatura.

Entendemos por competencia literaria la adquisición sociocultural del intertexto, determinado por la involucración del receptor, así como de la perfectibilidad de la producción cognitivo-intencional de la especificidad literaria.

Y damos un paso más: entendemos por competencia literaria la adquisición sociocultural del intertexto, determinado por la involucración del receptor, así como de la perfectibilidad de la producción cognitivo-intencional de la especificidad literaria, adquisición desarrollada en acto y correlacionada con el horizonte de competencias genérico-instrumentales.

Y aún forzamos un último paso: entendemos por competencia literaria la adquisición sociocultural del intertexto, determinado por la involucración del receptor, así como de la perfectibilidad de la producción cognitivo-intencional de la especificidad literaria, adquisición desarrollada en acto y correlacionada con el horizonte de competencias genérico-instrumentales tanto para la optimización de los mensajes en el marco de la competencia comunicativa como para la culminación del singular proceso didáctico de la literatura en su triple dimensión (ontológica, social-axiológica y academicista).

\section{REFERENCIAS BIBLIOGRÁFICAS}

ACTIS, B. (1998). Literatura y escuela. Rosario: Homo Sapiens.

AGUIAR E SILVA, V. M. (1980). Competencia lingüística y competencia literaria. Madrid: Gredos.

BERRUTO, G. (1979). La semántica. México: Nueva Imagen. 
BIERWISCH, M. (1970). «Poetics and linguistics». En Freeman, D. (ed.). (Título original: «Poetik und linguistk». En Kreuzer, H. y Gunzenhauser, R. (eds.) (1965): Mathematik und dichtung. Munchen: Nymphenburger Verlags handlung), 96-115.

BLAS ARITIO, F. de A. (2007). «La formación profesional basada en la competencia». Avances en Supervisión Educativa, 9, 1-10.

BOMBINI, G. (2006). Reinventar la enseñanza de la lengua y la literatura. Buenos Aires: Libros del Zorzal.

CAMPA, H. de la (2007). Diecinueve cuentos no premiados y comentados y sugerencias didácticas para enseñar a escribir un cuento. Granada: GEU.

CERRILLO, P. C. (2007). Literatura infantil y juvenil y educación literaria. Barcelona: Octaedro.

CHICHARRO, A. (1987). Literatura y saber. Sevilla: Alfar.

- (2006). El corazón periférico: sobre el estudio de literatura y sociedad. Granada: Universidad.

COLOMA MAESTRE, J. (2002). «Animación a la lectura: animación a la interculturalidad». En El español, lengua del mestizaje y la interculturalidad. AESLE, Actas XIII, 228-237.

CULLER, J., (1975). Poética estructuralista. Barcelona: Anagrama (Structuralist poetics. London: Routledge and Kegan Paul).

DELIA VIVANTE, M. (2006). Didáctica de la literatura. Buenos Aires: Magisterio del Río de la Plata.

DIJK, T. A. (1972). Some Aspects of Text Grammars. A Study in Theoretical Linguistics and Poetics. Paris: Mouton.

DIJK, T. A. (1976). «Aspectos de una teoría generativa del texto poético». En Greimas (ed.), Ensayos de semiótica y poética, 240-271. Barcelona: Planeta.

FLEMING, M. (2006). «Towards a Common European Framework of Reference for Languages of School Education?». International Conference. Council of Europe, Language Policy Division, and the Jagiellonian University. April, 1-12.

FRUGONI, S. (2006). Imaginación y escritura. Buenos Aires: Libros del Zorzal.

GARCÍA MADRAZO, P. G. y MORAGÓN, C. (1991). Literatura. Madrid: Pirámide.

GARCÍA RIVERA, G. (1995). Didáctica de la literatura para la Enseñanza Primaria y Secundaria. Madrid: Akal. 
GIRÓN, M. ${ }^{a}$ S. y VALLEJO, M. A. (1992). Producción e interpretación textual. Medellín: Editorial Universidad de Antioquia.

GÓMEZ-VILLALBA BALLESTEROS, E. et al. (2000). El desarrollo de las capacidades de los alumnos de Educación Primaria en el área de lengua castellana y literatura. Granada: Grupo Editorial Universitario.

GONZÁLEZ LAS, C. (1999). La lengua, instrumento de comunicación. Granada: Grupo Editorial Universitario.

HYMES, D. 1971. «Competence and performance in linguistic theory». En Acquisition of languages: Models and methods, 3-23. New York: Academic Press.

- (1974). «Hacia etnografías de la comunicación». En Antología de estudios de etnolingüística y sociolingüística, 48-89. México: UNAM.

- (1999). «Acerca de la competencia comunicativa». Forma y función 9, 13-37.

ISER, W. (1989). El acto de leer. Madrid: Taurus.

LLEDÓ, E. (2000). El surco del tiempo: meditaciones sobre el mito platónico de la escritura y la memoria. Barcelona: Crítica.

MATA, J. (2004). Cómo mirar la luna. Barcelona: Graó.

- (2008). «La edad de Aquiles o la futilidad de la literatura». En C. Lomas, (coord.), Textos literarios y contextos escolares, 119-134. Barcelona: Graó.

MENDOZA, A. y PASCUAL, S. (1988). «La competencia literaria, una observación en el ámbito escolar». Tavira, 5, 25-53.

MENDOZA FILLOLA, A. (1998). Tú, lector. Aspectos de la interacción texto-lector en el proceso de lectura. Barcelona: Octaedro.

- (1999). «El tratamiento didáctico de la literatura desde una perspectiva intertextual». En A. Romero y otros (eds.), Educación lingüística y literaria en el ámbito escolar, 21-44. Granada: GEU.

- (2004). La educación literaria. Bases para la formación de la competencia lecto-literaria. Málaga: Aljibe.

MORENO, V. (2008). «Literatura para ser leída, imitada y transformada». En C. Lomas, (coord.). Textos literarios y contextos escolares, 179-208. Barcelona: Graó.

NAVARRO, J. M. (1992). «La enseñanza de la literatura en el D.C.B.». En P. Cerrillo, y J. García Padrino (coords.), Literatura infantil y enseñanza de la literatura, 53-58. Cuenca: Universidad de Castilla-La Mancha. 
NÚÑEZ DELGADO, P. (2003). Didáctica de la comunicación oral: Bases teóricas y orientaciones metodológicas para el desarrollo de la competencia discursiva oral en la educación obligatoria. Granada: GEU.

- (2009). «Sobre la necesaria presencia de la literatura en la Educación Infantil. Algunas consideraciones estéticas y axiológicas para fundamentar una didáctica». Alhucema. Revista Internacional de Teatro y Literatura, julio-diciembre, 22, 132-157.

NÚÑEZ DELGADO, P. y ROMERO LÓPEZ, A. (2003b). Investigación en didáctica de la lengua e innovación curricular. Granada: Universidad de Granada.

OLSBU, I. y SALKJELSVIK, K. S. (2006). «La literatura en clase: Leer hacia la competencia literaria». I Congreso Nacional ANPE: 2006, año español en Noruega: un reto posible. ANPE, 1-7.

PERDOMO LÓPEZ, C. A. (2005). «Sobre la enseñanza de la literatura y la formación de la competencia literaria». En M. Abril Villalba (coord.). Lectura y literatura infantil y juvenil, 149-170. Málaga: Aljibe.

POZUELO YVANCOS, J. M. ${ }^{a}$ (1996). «Canon: ¿estética o pedagogía?». Ínsula, 600, 3-4.

REYZÁBAL, M. V. y TENORIO, P. (1994). El aprendizaje significativo de la literatura. Madrid: La Muralla.

RIENDA, J. (2006a). Cuaderno didáctico para el libro El buen amigo. Granada: Port-Royal.

- (2006b). Cuaderno de composición escrita. Granada: Port-Royal.

- (2007a). «Contestación al Discurso de Ingreso en la Academia de Buenas Letras de Granada de D. José Ignacio Fernández-Dougnac». En J.I. Fernández-Dougnac, Sobre la recepción poética de los Plomos del Sacromonte (Siglos XVI y XVII), 29-34. Granada: Academia de Buenas Letras.

- (2007b). El sueño legible. Disertaciones sobre educación y literatura infantil. Granada: Academia de Buenas Letras.

RODRÍGUEZ, J. C. (1994). La norma literaria. Granada: Diputación Provincial.

ROMERA CASTILLO, J. (1988). Didáctica de la Lengua y la Literatura. Madrid: Playor.

- (1999). Enseñanza de la lengua y la literatura. Madrid: UNED.

ROMERO LÓPEZ, A. (1989). Técnicas didácticas para la enseñanza de la composición escrita en Educación Básica. Granada: Universidad. 
ROMERO LÓPEZ, A. y RUIZ ORTEGA, F. (1999). «Educación literaria y expresión escrita». En A. Romero y otros (eds.), Educación lingüística y literaria en el ámbito escolar, 282-292. Granada: GEU.

- (2001). Acercamiento al texto poético: un programa de intervención didáctica para la Educación Primaria. Granada: GEU.

SCARDAMALIA, M. y BEREITER, C. (1992). «Dos modelos explicativos de los procesos de composición escrita». Infancia y Aprendizaje, 58, 43-64.

STUBSS, M. (1988). Lenguaje y educación. Madrid: Cincel.

TABERNERO, R. y DUEÑAS, J. D. (2003). «La adquisición de la competencia literaria: Una propuesta para las aulas de Infantil y Primaria». En A. Mendoza y P. Cerrillo (coords.), Intertextos: Aspectos sobre la recepción del discurso artístico, 301-335. Cuenca: Universidad Castilla-La Mancha.

THOMAS, J. J. (1978). «Teheorie genérative et poétique littérarire». Languages 51, 7-64.

TUXWORTH, E. (1989). Competency based education and training. En J. W. Burke (ed.). London: Falmer Press.

WHANÓN BENSUSAN, S. (1991). Introducción a la historia de las teorías literarias. Granada: Universidad de Granada.

Recibido el 2 de junio de 2013.

Aceptado el 19 de septiembre de 2013. 
